\title{
Towards iTV services for older people: exploring their interactions with online video portals in different cultural backgrounds
}

\section{Authors' Accepted Version}

\author{
Susan Ferreira ${ }^{a}$, Sergio Sayago ${ }^{b}$, Josep Blat ${ }^{a}$ \\ ${ }^{a}$ Interactive Technologies Group, Universitat Pompeu Fabra \\ RocBoronat, 138, E-08018, Barcelona, Spain \\ susan.moller@upf.edu, josep.blat@upf.edu \\ ${ }^{b}$ Human-Computer Interaction Group, Universitat de Lleida \\ Jaume II, 69, ,25001 Lleida, Spain \\ sergio.sayago@diei.udl.cat
}

Citation: Ferreira, S., Sayago, S., Blat, J. (2014). Towards iTV services for older people: exploring their interactions with online video portals in different cultural backgrounds.

Accepted for publication (29-October-2014) in Technology and Disability.

\begin{abstract}
With a growing ageing population and the advent of interactive TV (iTV), understanding how older people use iTV services is a timely and important task. Working towards this end, this paper reports on in situ conversations of, and observations with, almost 400 older people, with different levels of educational attainment and experience with ICTs, while talking about and using online video portals and similar interactive systems in Spain, Brazil and Denmark. The results show more similarities than differences in their reasons for adopting online video portals and patterns of use. All our participants used these portals for keeping or remaining in touch with people they trusted. The results also show that privacy online was a common concern to all the participants. Differences in the acceptance of e-government services and the type of content that drove most of their interactions were also found. Implications for designing more accessible and meaningful iTV services are discussed.
\end{abstract}

Keywords: Ethnography, older people, cross-culture, iTV, online video portals. 


\section{Towards iTV services for older people: exploring their interactions with online video portals in different cultural backgrounds}

\section{Introduction}

With a growing ageing population and the advent of interactive TV (iTV), there are reasons to argue that understanding how older people $(60+)$ use iTV services is a timely and important task. iTV opens up numerous opportunities for communication and access to online information/services, which could (and should) be of great benefit to older people. Communication serves key functions in ageing, such as reducing isolation, and having access to online information and services is seen by many as paramount to enable older people to remain fairly independent and (digitally) engaged in today's society. However, most of them run the risk of being unable to access and make the most of these services, due to their either lack of or little experience with ICTs, and a tendency to exclude them from technological developments [1]. In our research, we aim to design more accessible and useful iTV-based communication and information seeking services for, and with, older people.

Working towards this goal, we address in this paper the question of how older people interact with online video portals. We started by exploring the relationship between older people and noninteractive and digital TV. Yet, those older people who participated in a number of user studies were concerned about us conducting in situ observations of how they watched TV at their home. Thus, we decided to explore how they interacted with online TV portals. We considered that doing so could (and should) aid in conceiving better iTV services for the older population, since online video portals are increasingly popular [2] and can be regarded as an implementation of iTV [3].

In this paper, we report on in situ conversations and observations we conducted with older people, who were motivated to learn and use online video portals and other related technologies, such as OSN (Online Social Networks), in three countries, Spain, Brazil and Denmark. Older people are often described as a (very) heterogeneous user group, and doing user studies in different countries could (and should) help us understand how similar or different older people are in terms of their attitudes towards and interactions with online video portals. In Spain, we conducted fieldwork activities in a highly participatory adult learning community in Barcelona over a 3-year period. 201 participants were involved in the study conducted in the city of Barcelona. In Brazil, we conducted first-hand observations of and conversations with 78 participants while they went about using computers during a month in a center that runs computer classes to older people. We also conducted 13 home interviews in Brazil. In Denmark, the fieldwork was performed over a 4-month period, including 78 participants from two different social centers, and 13 participants, who took part in home interviews.

Overall, and perhaps surprisingly, a key and common finding to the three user studies is that participants exhibited more similarities than differences in their use of online video portals, despite their different cultural backgrounds. All of them saw in online video portals an opportunity to foster socialization and communication. They also showed strong concerns about privacy. We found differences too, especially in the participants' interest in e-government services.

The remainder of the paper is organized as follows. Section 2 presents a literature review on older people, iTV and cross-cultural HCI related to the objectives of the paper. Section 3 describes our study and Section 4 presents the main results. Section 5 summarizes the results and discusses them 
along with the methodological approach. Section 6 closes with the main conclusions and future work perspectives.

\section{Related work}

\subsection{Older people and iTV}

Previous studies have mostly concentrated on developing prototypes for communication (e.g. [4] and [5]). Svensson et al [4] address the social isolation of older people and the importance of TV in their lives. They argue that TV is a central piece of furniture in older people's living room, and that watching TV is an activity they enjoy most at night. Svensson et al introduce the concept of "ticketto-talk". This concept assumes that everyday activities, such as going for a walk, gardening, reading and watching TV, provide (older) people with an opportunity to start a conversation and socializing with others. They discuss the potential use of iTV as a resource for social interaction, and propose a prototype that aims to facilitate and stimulate the communication amongst older people while watching TV. They also stress the importance of identifying future services and applications that support the development of social relations among senior citizens. Rice and Alm [5] carried out two studies aimed to identify older people's areas of interest for iTV applications and how they would use them. By conducting theatre and paper prototyping, the participants showed a big interest in keeping in touch with family and friends. Rice and Alm compared the use of new navigational layouts with the traditional iTV interaction, and evaluated four prototypes of communication systems for sharing multimedia contents. The results show that older people had difficulties in understanding some of the terminology and interactive concepts used in traditional design. The results also indicated a number of weaknesses in the design of more conventional layouts. Their research indicates that techniques that mimic aspects of the real world are possible new directions towards designing digital TV interfaces. Rice and Alm stress the fact that "significant work is still needed to design interfaces that can support the elderly population skills and abilities" [5]).

Other studies have focused on the opinions of older people about iTV. Kurniawan [6] studied the reasons that make digital TV unappealing to them. Three older women were interviewed. The youngest one was 69 -years-old. One of the issues raised by these older women was that on-demand movies are not appropriate for older people, as the movies contain inappropriate language and excessive sexual and violent scenes. The older women also indicated that the tasks were very complex (e.g. multiple screens, moving text, extra remote control). Other barriers were the cost of digital TV systems and a perceived lack of human support. Papa [7] conducted focus groups to explore and analyze the user experience of older people with digital TV and, in general, with future services enabled by broadband ICTs. The results show the influence that aspects such as the technological equipment available at home, the attitude towards digital technology and lifestyles can have on older people's interaction with digital TV.

While there is growing awareness in Human-Computer Interaction (HCI) that studying interactions as they occur (i.e. in out-of-laboratory conditions) is worthwhile to design better interactive technologies [8], none of the studies reviewed above have studied in situ the interactions of older people with online TV sites.

\subsection{Cross-cultural HCI with older people}

With ICTs being used almost worldwide, the importance of understanding cultural similarities and differences in how people use them is important. However, very little cross-cultural HCI research has been conducted with older people. Previous studies have primarily focused on cultural variation amongst developed (European) countries ([9], [10] and [11]). To the best of our knowledge, a few of them have taken into account countries with different levels of development ([12], [13]), despite the importance of conducting user studies in these countries to help to improve the quality of lives of their people and the uptake of ICTs. Schibelsky [12] focused on Brazil and argued that while 
many countries are considering questions related to personalization and bringing TV closer to the PC functionalities, in Brazil, it is important, at least, as a first step, to see TV as a mass and collective media before thinking in terms of digital TV services. Sa-nga-ngan [13] studied older people's browsing behavior in the UK, US and Thailand, finding that older people in developing countries had more difficulties in browsing than did those living in more developed ones.

\section{Description of the study}

\subsection{Motivation and objectives}

"The major open research question in iTV is when, and how much audiences want to interact with devices, content, and other people" [3]. In our study, we approached this question from an HCI perspective, and addressed it by focusing on:

(a) identifying the accessibility issues that hinder more severely the interactions of older people with online video portals;

(b) examining how they interact with and use these portals in out-of-laboratory conditions;

(c) exploring cultural differences and similarities in (a) and (b) in developed and developing countries.

\subsection{Research approach}

We conducted three user studies, involving 393 participants. They can be considered a heterogeneous user group, as it is composed of people with different levels of educational attainment, ranging from primary (children) to secondary school (i.e. before college), and previous experience with ICTs, ranging from three months to more than 10 years using these technologies. The studies were conducted in Spain, Brazil, and Denmark. Table 1 describes the data gathering methods and describes briefly the settings where the studies were conducted. We provide key aspects related to the research approach adopted in each user study next.

The study conducted in Barcelona was the core of the research ${ }^{1}$. We conducted a 3-year (20102013) ethnographical study in Àgora, an adult educational center. Over this period of time, the first author participated in 14 computer courses and 16 drop-in sessions, resulting in a total of 234 hours of fieldwork with 201 older people (aged 60 to 85; women: 113; men: 89) with different levels of experience with ICTs. They reported having been using these technologies for about three months to six years. Informal conversations revealed that the participants were born in different Spanish regions and had low levels of educational attainment (70\% finished primary school). Since Àgora follows a very participative and learner-centered methodology [14], the courses and drop-in sessions took into consideration the daily needs and interests of older people. Thus, most of the activities conducted in our study focused on meeting their needs, which were, amongst others, to know more about CMC (Computer-Mediated Communication) tools, such as the e-mail, and seeking information and resources online, as well as tools for editing multimedia content. Questionnaires and dairies were also administered to the participants to enrich our observations and informal conversations. 8 participants ( 4 men, 4 women) filled in the diaries over a 1-week period. The questionnaire consisted of 24 questions. 21 ( 8 men, 13 women) participants filled it in.

In Brazil, the study lasted 2 months $^{2}$ and it was divided into two stages. In the first stage, we conducted, over a month, a (rapid) ethnographical study [15] with 78 participants (aged 60 to 80; women: 43; men: 35) in Caso do Idoso, a center where older people take computer classes and perform other social activities. Most of them reported not holding a university degree. 44 participants were enrolled in an introductory course to ICTs and 34 in the advanced level course.

\footnotetext{
${ }^{1}$ Since the first author is current doing her $\mathrm{PhD}$ research in Barcelona.

${ }^{2}$ This study was done while the first author conducted a 2-month research stay in Brazil
} 
The latter reported having more than 1 year of experience with ICTs. During this period, the first author observed the interaction of the participants with Skype, e-mail systems and OSN. She also conducted observations of them searching for content and using multimedia editing tools. The observations resulted in c. 60 hours of fieldwork. In the second stage of the study, she conducted 13 home interviews about older people's use of TV, mobile phones, tablets PCs, computers and opinions regarding iTV services. These interviews aimed to deepen and widen the observations and informal conversations.

Similar methods were conducted in a four-month ethnographical study in two adult educational centers, Borger and FoF, both in Denmark. 78 participants (aged 60 to 91; women: 42; men: 36) participated in this study. Their level of education was similar to that of the Brazilian participants. 50 Danish participants took ICTs courses for beginners, while 28 participants were enrolled on the advanced ICT course. These participants reported having more than 3 years of experience with ICTs. During the study, the first author observed how the participants interacted with e-mail systems and Youtube, and with e-shopping and e-government platforms. The observations resulted in 29 hours of fieldwork. Home interviews (similar to those conducted in Brazil) were also carried out in Denmark with 13 participants (aged 60 to 72).

As shown in Table 01, in the three settings, we ran similar participatory design (PD) sessions related to online video portals, wherein the participants were asked to create their own video portal interface. Although these sessions had a common structure, summarized next, the activities were adapted to the characteristics of each setting, such as language, popular TV channels and tools the participants were familiar with. Firstly, examples of video sharing sites (such as Youtube or Vimeo) and video on demand portals from local TV channels were presented to the participants. Secondly, the participants created their own prototype. They did so by re-designing several key interaction elements of these portals, such as content searching and video recommendation modules, and functions for giving feedback and writing comments. Finally, these participatory design activities were aimed at stimulating the discussion about the video portals and envisioning future interaction possibilities, and participants voiced their opinions about these two aspects.

\subsection{Data gathering and analysis}

Fieldnotes were taken mostly immediately after the sessions in the courses and PD activities, due to the active participation of the first author in most of them. The analysis of the fieldnotes follows the interpretation of Nigel Gilbert (Researching Social Life) [16] of Strauss and Corbin [17] Grounded Theory's methodology. The main results are presented next.

\section{Results}

\subsection{Similar interests, concerns and interactive practices}

\subsubsection{Online video portals}

In the participatory design session in Àgora, $79 \%$ of the participants indicated that a sharing function was indispensable in online video portals, and our observations conducted throughout the length of the study helped us understand their opinion, since they used online video portals mostly for strengthening, enriching and reestablishing contact with people they trusted.Their communication focuses on members of their local community, especially close friends and relatives (i.e. children, grandchildren and nephews). They were concerned about trust, which concurs with the results of previous works addressing OSN and older people ([18] and [19]), highlighting a desire of older people to share information selectively and an overall lack of interest in communicating with unknown people through OSN. This video-mediated communication adopted two styles, one-to-one and one-to-many, involving face-to-face and online conversations. E-mails and posts in OSN were the triggers of this communication. They started either online conversation, 
by replying the message, or enriched face-to-face ones, as sending or receiving links to video often triggered a face-to-face conversation about the content of the video or their personal experiences related to it. Àgora participants adopted different roles in this communication, ranging from receiving and watching videos to creating and sharing videos. This active behavior was especially apparent amongst those participants with more experience with ICTs.

Àgora participants looked for online videos using different strategies, which vary according to their familiarity with the video content. When searching for a specific content, the participants typed in keywords of the video in the search bar. When they were exploring the videos available on the portals, they used the categories menu. In terms of usability and accessibility, we identified several issues regarding the registration processes and sharing content. The participants with little ICT experience had difficulties filling in the forms (such as not understanding what information they had to provide, spelling and day format mistakes) when creating accounts and could not register without the support of other participants and/or the researcher. The main accessibility issues for content sharing were due to elements of the user interface that were not visible enough for them. Sharing options might become visible only when unfolding a menu or scrolling down the page, which requires an exploratory and active user behavior, which was difficult to see amongst older people with little ICT experience.

Caso do Idoso (Brazil) participants were very interested in online video portals because they were already familiar with watching videos on TV. Conducting important tasks, such as reproducing videos, was easy for all of them. Regarding searching and sharing content, passive and active roles were identified too. Most of the Caso do Idoso participants, probably due their little experience with ICT, exhibited a more passive behavior than did participants in Spain. In Casa do Idoso, participants watched videos they received by e-mail, without directly interacting with the portals. Around 5\% of them exhibited a more active participation, searching for videos of their interest, as this participant put it in a participatory design session [68, Fb15] "I often watch videos on the Internet. I like it a lot and watch all kind of videos. I especially like handcraft videos, last month I learned to do some handmade boxes with them." Similar results were found in the in situ interviews, in which $40 \%$ of the Internet users claimed to watch videos on the web, but only $20 \%$ reported looking for them, as the following extract illustrates [70, FbII14] "Sometimes I watch videos on YouTube. People usually send them on to me by e-mail, I don't have time to search for videos." Online videos triggered intergenerational (with family members) and community (between friends and colleagues) communication. This communication took place face-to-face and online, both triggered by receiving a video, especially by e-mail.

Watching films and videos was a common activity among Danish participants. Informal conversations with them revealed that they did so, for instance, when they met up in the center to watch an old movie about the city. They also reported watching a musical while being at home or videos in museum displays. Regarding online videos, most of the participants acknowledged not being used to looking for content on video sharing sites, like YouTube. Conversations with the instructors at the center, which were backed up by our observations, revealed that some participants received links to videos by e-mail and also watched videos embedded in other web pages, such as a video about fishing in a portal for buying fish online. $61 \%$ of the participants reported watching videos on the computer at home in the in situ interviews.

\subsubsection{Multimedia content and online communication channels}

Creating and editing multimedia content was a frequent activity amongst all the Àgora participants, as well as a motivation for them to learn ICTs. Courses on MS Power Point, photo edition or calendar creation were part of the ICT activities organized in Àgora. Most of the participants were also motivated to share the multimedia contents they created, as illustrated by this participant in an Introduction to ICT course, [72, M11]: (showing the researcher 4 calendars that he created with 
pictures) "These two are very similar but the size of this file is smaller, which helps me to send the calendars by e-mail to the people that usually e-mail me."

Online communication and working with multimedia content were also of great interest to the Casa do Idoso participants. From our observations and the interviews with teachers, editing pictures was a source of motivation for them to keep learning about ICTs; namely, how to look for, edit and share online content with people they knew. Concurring with previous results gathered with participants in Àgora (Spain) [20], the e-mail was the most popular Internet application amongst the least and more experienced Brazilian participants. Indeed, Facebook was the second most popular communication tool, especially among the participants with more experience with ICTs, who also used Skype for keeping in touch with family members living abroad. In the in situ interviews, 70\% of the Internet users reported using the e-mail. Half of them reported using social network sites and Skype too.

Communication was very important amongst Danish participants, who were highly motivated to use, and, indeed, often interacted with, online applications to keep in touch with close friends and relatives. All the participants reported using the e-mail in the in situ interviews. Halt of them (54\%) also used Skype, and 38\% claimed to use OSN. Editing personal photographs on the computer was a very popular activity too. This popularity manifested itself in the activities carried out in the center, such as photo edition and creation of MS Power Point presentations, and it was confirmed in our conversations with the instructors and participants. The main reasons for editing and creating multimedia content can be divided into three categories: (a) keeping a digital record of the family to be circulated amongst the younger generations, such as grandchildren, (b) keeping memories of trips and (c) digitizing paper-based materials related to their hobbies or interests. $61 \%$ of the participants pointed out during the interviews that they edited photographs at home as well.

\subsubsection{Privacy}

All Spanish participants reported feeling uncomfortable with OSN when they were unsure about who could read their posts. Privacy was also an important concern amongst Brazilian participants. They needed to feel in control of the technology to decide who could see what. The comment from one participant in the in situ interviews is representative of that: [71, MbII] "I use Facebook but not very often. When I receive something I answer, but adding things is very difficult for me and I don't do it. I don't know how it works well, so I avoid doing stupid things. I prefer to just see other people's contents. If you make your own things public...that is dangerous." They did not feel comfortable when sharing content online with people they did not know - close groups were preferred (e.g. friends on Skype, Facebook or sending an e-mail to a group of people).

Similar issues were identified in the two centers in Denmark. All the instructors pointed out that privacy was an important concern amongst the Danish participants. They disliked the idea of not having control over what people could get to see and know about them online. They refused pointblank to publish content in OSN. They preferred private strategies of communication. As one of the participants put it in a semi-structured interview, [70, Fd15]: 'I don't use Facebook. It's dangerous. I tell my son to never ever put a picture of me on that. People should not put their personal things there, like if you are going to travel for example."

\subsection{Differences in the contents of the interactions and use of e-government services}

The Brazilian participants' interaction was content dependent, i.e. they were more interested in searching, editing or sharing content, such as videos, which appealed to them, regardless of this content being more or less socially popular (e.g. clicks on 'I like it'). This behavior concurs with the one we found amongst Àgora participants in Spain. In particular, and as one might expect, the topic of family was of interest to all the participants (in Spain, Brazil and Denmark), as it has become evident in, for instance, their use of online video portals for keeping in touch with relatives. Yet, 
there were (cultural) differences. For instance, religion was a far more popular topic amongst Brazil participants than either Spanish or Danish ones.

Interviews with participants in Denmark and instructors revealed that they were highly interested in e-government (e.g. paying taxes online and e-health), Internet banking or online shopping. In an interview, one of the instructors explained the main reason for the participants' interest in egovernment: [50, MdI03] "Nowadays, all my students want to learn about netbanking and internet, even the ones that know nothing about computers. In Denmark, in these days you can only buy flight tickets online. By 2016, the goverment aims to interact with Danish citizens via online services. Many of them are scared." Neither Spanish nor Brazilian participants showed such an interest in e-government, perhaps, because they are not so strongly pushed to do so or have not perceived the need of doing it yet.

\section{Discussion}

We summarize the findings in 5.1. Afterwards, in 5.2, we discuss the view of older people portrayed in the results. We argue that this view has a number of implications for designing online video portals (and iTV services) for a growing older population, and we discuss them in 5.3.

\subsection{Summary of the results}

In Section 1, we made the case for addressing the interactions of older people with online video portals, hoping that doing so would help us work towards designing more accessible and meaningful iTV services. In Section 2, we showed that there was room for understanding further the relationship between older people and iTV. We considered that adopting an ethnographical approach, such as the one described in Section 3, and conducting user studies with older people with different cultural backgrounds, could help us attain, at least, partially, this goal, and the results, presented in Section 4 and summarized next, seem to confirm it. All our participants used online video portals mostly for strengthening, enriching and reestablishing contact with people they trusted. Creating and editing multimedia content that enabled the participants to keep and share a digital record of the family and memories of trips was also a common practice amongst all our participants, strengthening the relevance of communication. Yet, none of them feel at ease at the prospect of strangers having access to their personal contents. Differences in the content of the online videos or, in general, digital content, that appealed the participants most differed depending on their cultural background, as well as their interest in using e-government services.

\subsection{A different view of older people: active and not so different as we might think}

Whilst our literature review has shown that the relationship between online video portals and older people has received little research attention, we found that all our participants used online video portals mainly for keeping in touch with relatives and friends. The relevance of communication might be expected, since communication is very important in ageing. Also, other studies have highlighted the relevance of communication in the adoption and use of ICTs by older people (e.g. [21], [5]). Yet, using a technology, in this case, online video portals, which have not been particularly designed to establish one-to-one or one-to-few conversations, as a means of enriching and establishing them, portrays older people as active appropriators of ICTs. This view is at odds with the typical passive role attributed to older people in previous research, especially when looking for information online without creating new digital content. This might be due to the profile of our participants and warrants further research.

We have argued that very little cross-cultural HCI research with older people has been conducted thus far. This begs the question of whether looking at cultural aspects in ICT use by older people is possible and, if so, how it takes forward current HCI research with them. As opposed to the previous studies reviewed in Section 2, which have not framed the research in situations of daily 
technology use over time, by adopting an ethnographical approach, i.e. conducting observations and conversations with older people with different cultural backgrounds in different communities over months and years, we have found more similarities than differences in their relationship with online video portals. This suggests that older people might not be such a heterogeneous user group, at least when we look at their interactions with online video portals (and other ICTs, such as OSN), from an ethnographical lens.

The former claim deserves further discussion, especially if we consider the broad age range of our participants (60-91). The main difference between the youngest and oldest participants (75+) was due to the impact of normative age-related changes in functional abilities, mainly cognition and hand-eye coordination, on conducting instrumental tasks. The oldest participants struggled to use the mouse and tended to be slower than the younger ones in completing tasks. However, as far as their reasons for using online video portals, concerns about privacy and interest in communication are concerned, no differences were observed, which suggests a number of implications for designing iTV services, discussed below.

\subsection{From online video portals to iTV services: some implications}

Regardless of age, and their previous experience with ICTs, all our participants showed interest in, and were capable of using, online video portals. This indicates that this technology could help us reinforce the digital inclusion of older people and foster the ICT uptake in a meaningful way within this segment of the population, especially in developing countries, where older people might have more difficulties to access ICTs. By sharing content - which might be culturally either dependent, such as religion in the case of Brazil, or independent, as in the relevance of the family - older people are likely to enrich their communication with their relatives and/or close friends, and this can aid in reducing their social isolation and fostering their participation in social activities. Accessing on videos on demand that are related to their personal interests through iTV could also be an opportunity to facilitate the access of online/digital information to older people, given that most of them still might not know how to use computers, but are fairly familiar with TV.

\section{Conclusions and next steps}

This paper has addressed the cross-cultural interactions of a large number of older people with different levels of educational attainment and previous experience with ICTs with online video portals from an ethnographical perspective. The results have presented more similarities than differences in their motivations for using online video portals and patterns of use. The results have shown that the older adults who participated in our studies in Spain, Brazil and Denmark, use online video portals mainly for enriching and establishing communication with people they trust. Contrary to common, passive views of older people and ICTs, the results have presented them as potential digital content creators and shown they can have strong motivations for sharing content online. A number of implications for designing more accessible and meaningful iTV services for a growing (and cultural diverse) older population, and for framing older people within HCI research, have been drawn from the results. The findings also show the potential of ethnography, which has seldom adopted in the previous and related studies reviewed in this paper.

Regarding our future work perspectives, the results suggest that online video portals can contribute to reduce digital and social exclusion amongst the older population, and we consider that this warrants further research. We plan to address it by delving into the communication triggered by sharing online videos. We also aim to look into how older people create digital videos, since this can potentially take forward our understanding of HCI, as a whole, and with this user group, in particular. Finally, the cultural layer of older people's interactions seems to have a lot of potential 
and we plan to deepen our research by understanding what aspects or dimensions of culture impact most or least in their ICT use.

\section{Acknowledgments}

We thank all the participants, volunteers and members of the staff of Àgora, Caso do Idoso, Borger and FoF for their participation in our research. We also thank our colleagues at the Interactive Technologies Group and Aalborg University in Denmark for their collaboration. We thank Mai Baunstrup for her collaboration while developing and conducting the home interviews in Denmark. This work has been partially funded by Life 2.0: Geographical positioning services to support independent living and social interaction of elderly people (CIP ICT PSP-2009-4-270965), the WorthPlay project (funded by Fundación General CSIC and la Caixa Obra Social) and the EEE (TIN2011-28308-C03-03) project. The first versions of this paper were written when one of us was granted an Alliance 4 Universities Fellowship (A4U). We also acknowledge the support from the Ministry of Foreign Affairs and Cooperation and the Spanish Agency for International Development Cooperation (MAECAECID).

\section{References}

1. Newell, Alan F. "Design and the digital divide: insights from 40 years in computer support for older and disabled people." Synthesis Lectures on Assistive, Rehabilitative, and HealthPreserving Technologies 1.1 (2011): 1-195.

2. Burgess, Jean, and Joshua Green. "YouTube: Digital media and society series." Cambridge: Polity (2009).

3. Chorianopoulos, Konstantinos, and George Lekakos. "Learn and play with interactive TV." Computers in Entertainment (CIE) 5.2 (2007): 4.

4. Svensson, Marcus Sanchez, and Tomas Sokoler. "Ticket-to-talk-television: designing for the circumstantial nature of everyday social interaction." Proceedings of the 5th Nordic conference on Human-computer interaction: building bridges. ACM, 2008.

5. Rice, Mark, and Norman Alm. "Designing new interfaces for digital interactive television usable by older adults." Computers in Entertainment (CIE) 6.1 (2008): 6.

6. Kurniawan, Sri. "Older women and digital TV: a case study." Proceedings of the 9th international ACM SIGACCESS conference on Computers and accessibility. ACM, 2007.

7. Papa, Filomena, Bartolomeo Sapio, and M. Felicia Pelagalli. "User experience of elderly people with digital television: a qualitative investigation." Proceddings of the 9th international interactive conference on Interactive television. ACM, 2011.

8. Moggridge, Bill, and Gillian Crampton Smith. Designing interactions. Vol. 17. Cambridge: MIT press, 2007.

9. Blat, Josep, et al. "Cross-cultural aspects of ICT use by older people: preliminary results of a four-country ethnographical study." Proceedings of Irich Human Computer Interaction Conference Integrated Practice Inclusive Design, Korck. 2011.

10. Cortellessa, Gabriella, et al. "A cross-cultural evaluation of domestic assistive robots." Proc of the AAAI Fall Symposium on AI and Eldercare. 2008.

11. McKay, Elspeth. "Human-computer interaction closes the digital divide: a multicultural, intergenerational ICT case study." Proceedings of the 2005 South East Asia Regional Computer Science Confederation (SEARCC) Conference-Volume 46. Australian Computer Society, Inc., 2005.

12. Schibelsky, Lara, et al. "Understanding iDTV in a developing country and designing a Tgov application prototype." Proceedings of the 7th ACM conference on Designing interactive systems. ACM, 2008.

13. Sa-nga-ngam, Prush, and Sri Kurniawan. "A three-countries case study of older people's browsing." Proceedings of the 8th international ACM SIGACCESS conference on Computers and accessibility. ACM, 2006. 
14. Sánchez Aroca, Montse. "La Verneda-Sant Martí: A school where people dare to dream." Harvard educational review 69.3 (1999): 320-335.

15. Millen, David R. "Rapid ethnography: time deepening strategies for HCI field research." Proceedings of the $3 r d$ conference on Designing interactive systems: processes, practices, methods, and techniques. ACM, 2000.

16. Gilbert, Nigel, ed. Researching social life. Sage, 2008.

17. Corbin, Juliet, and Anselm Strauss, eds. Basics of qualitative research: Techniques and procedures for developing grounded theory. Sage, 2008.

18. Gibson, Lorna, et al. "Designing social networking sites for older adults." Proceedings of the 24th BCS Interaction Specialist Group Conference. British Computer Society, 2010.

19. Righi, V., S. Sayago, and J. Blat. "Older people's use of Social Network Sites while participating in local online communities from an ethnographical perspective." CIRN 2012 Community Informatics Conference: 'Ideals meet Reality. 2012.

20. Sayago, Sergio, and Josep Blat. "Telling the story of older people e-mailing: An ethnographical study." International Journal of Human-Computer Studies 68.1 (2010): 105120.

21. Dickinson, Anna, et al. "Introducing the Internet to the over-60s: Developing an email system for older novice computer users." Interacting with Computers 17.6 (2005): 621-642. 
Table

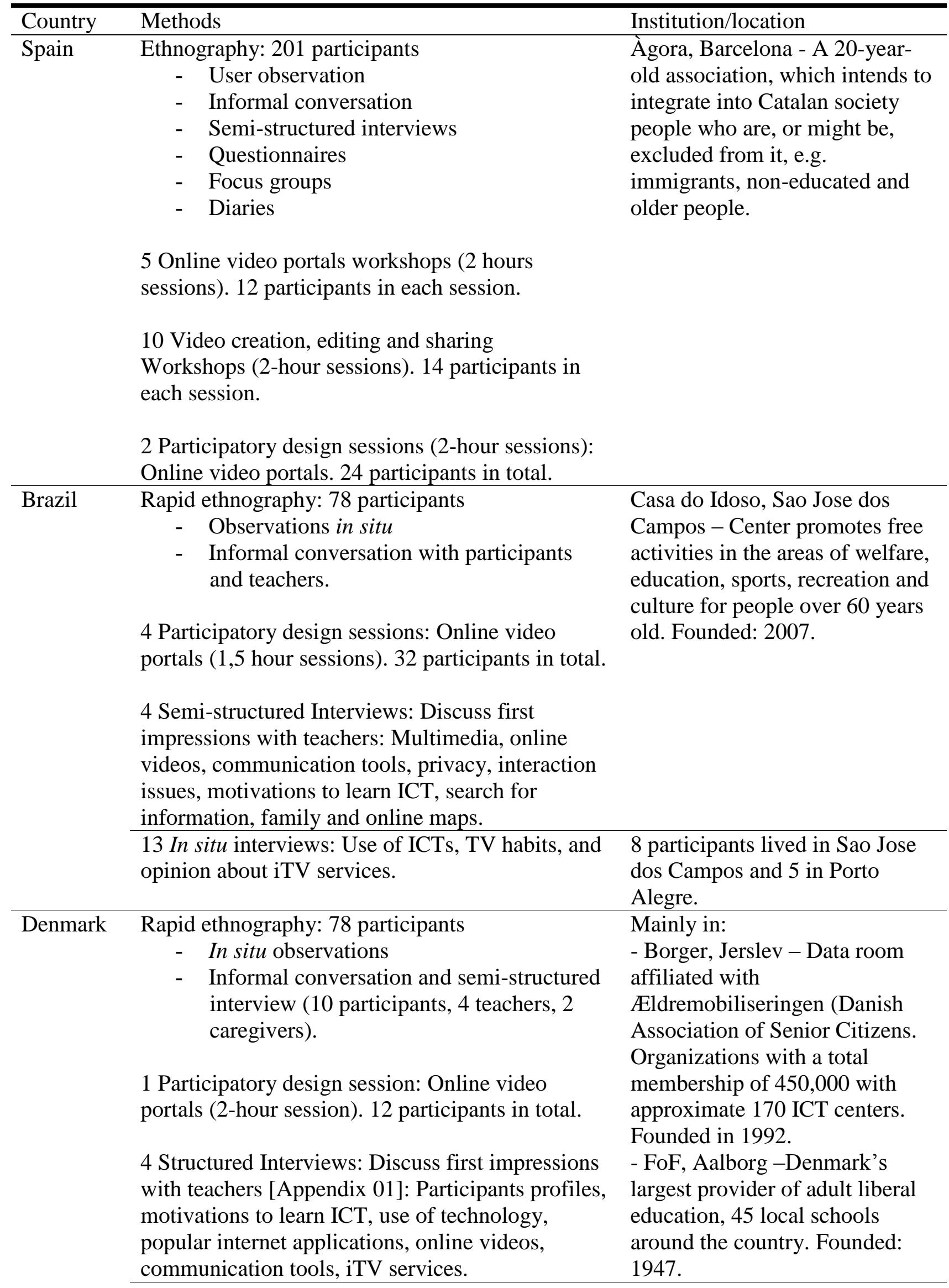


Table 1 - Data gathering methods and settings.

\section{Appendix 01 - Interview script}

\section{Profile teacher:}

1. For how long have you been teaching elderly?

2. Is this a volunteer activity or is your official job?

3. How old are you?

4. What is your education level?

5. In case of volunteer, what you use to do before?

\section{Profile of the participants:}

1. What are the participants age range?

2. Is there a age group that is more frequently? Ex.: 60-65, 65-70, etc...

3. Which education level is more frequently among the participants?

4. Are most of them retired or still work?

5. Which kind of job, intellectual or manual is more frequently between the participants?

\section{Motivation:}

1. What do you think is the main motivation for the elderly to come to the computer class?

2. Can you classify the motivation of the participants come to the class as principal motivation (1) to less relevant motivation (4).
a. Socializing with other participants
b. Learning computer
c. Being occupied
d. Feel included
e. Other

3. What do you think is the main motivation for the elderly to learn to use computer?

4. Can you classify the motivation of the participants to learn computer as principal motivation (1) to less relevant motivation (4). (necessary X entertainment) 
a. Learn practical things that are necessary for their life (netbanking, schedule a visit to the doctor, etc)

b. Communicating with family and friends

c. Entertainment (pictures editing, powerpoint)

d. Searching for information

e. Other

5. If you were asked to summarize what most of them use computers for, your answer would be:

\section{Computer use and frequency:}

1. Own computer: Someone else's computer

(Everybody - Majority - Half of them - Minority - None - I don't know)

2. The ones that don't have one, what do you think is the main reason for that?

(Maybe because: a) the person do not see the need for a computer, b) is not able to use a computer, or c) a computer is too expensive)

3. How often the participants usually use the computer after class?

Uses computer everyday Three times a week

Once a week Few times per month

Few times per year Never

4. Does most of them already use computer before coming to the class?

5. Do the children and grandchildren usually help them with the computer?

\section{TV on Internet}

1. Do they use/interest in TV through Internet?

2. Do they use/interest in YouTube?

3. Do they share/recommend videos? How? With whom?

4. Receive video recommendations from someone? How? From whom?

\section{Social Network:}

1. Have an account in: Facebook Twitter , others (Everybody Majority - Half of them - Minority - None - I don't know)

The ones that has it:

2. What is their motivation to use it?

3. How often they use them?

4. What they usually comment they like or dislike in Social Network?

5. Privacy concerns? (Publish public messages or pictures, add people that they don't know very much?) 


\section{Use of technology:}

Can you identify the use that the participants do of technology as: (Very interest - some how interested - not interested)

\begin{tabular}{|c|c|c|c|c|c|}
\hline & & & & & \\
\hline & Interest & Use & Interest & Use & \\
\hline E-mails & & & & & \\
\hline Skype & & & & & With whom? \\
\hline $\begin{array}{l}\text { Internet } \\
\text { services/ } \\
\text { Internet surfing }\end{array}$ & & & & & \\
\hline Net banking & & & & & \\
\hline E-commerce & & & & & \\
\hline ; & & & & & \\
\hline Image editing & & & & & \\
\hline $\begin{array}{l}\text { Sharing } \\
\text { pictures }\end{array}$ & & & & & $\begin{array}{l}\text { How? With } \\
\text { whom? }\end{array}$ \\
\hline $\begin{array}{l}\text { Downloading } \\
\text { pictures from } \\
\text { camera }\end{array}$ & & & & & \\
\hline $\begin{array}{l}\text { Searching for } \\
\text { information }\end{array}$ & & & & & Where? \\
\hline News & & & & & \\
\hline $\begin{array}{l}\text { r/Movies } \\
\text { program }\end{array}$ & & & & & \\
\hline Maps on Web & & & & & \\
\hline PowerPoint & & & & & $\begin{array}{l}\text { Share } \\
\text { presentation? } \\
\text { How? With } \\
\text { whom? }\end{array}$ \\
\hline Word & & & & & \\
\hline Excel & & & & & \\
\hline $\begin{array}{l}\text { Windows Movie } \\
\text { Maker }\end{array}$ & & & & & \\
\hline Mobile phone & & & & & \\
\hline Calling & & & & & \\
\hline SMS & & & & & \\
\hline Camera & & & & & \\
\hline MMS & & & & & \\
\hline E-mails & & & & & \\
\hline Internet & & & & & \\
\hline $\begin{array}{l}\text { Has used } \\
\text { touchscreen }\end{array}$ & & & & & \\
\hline $\begin{array}{l}\text { Traditional } \\
\text { phone }\end{array}$ & & & & & \\
\hline
\end{tabular}

\section{About ITV:}

1. Do you think the majority of them watch television often? 
2. If it was possible to include some functionality from the computer in the TV do you think they would be interested in using it? (Ex.: YouTube, Skype, e-mail, chat, buying from the TV, interactive TV programs (commenting, voting), etc...)

3. What do you think they would be more interested in having on the TV? Classify in: Very interest - some how interested - not interested.

- Recording,

- Pausing,

- Recommending programs,

- Commenting programs,

- Like/dislike programs,

- See other users opinions,

- Skype,

- Chatting with a friend, buying online,

- Searching for videos,

- Asking for more information about a topic,

- Sharing pictures,

- Internet applications

\section{Cross cultural Brazil-Spain}

In Spain and also in Brazil I could observe some things that I would like to verify if it is similar here or not...

1. What are the main difficulties they have to use the computer?

2. Privacy concern? Ex.: do they: comment on web pages (Facebook, YouTube, blogs) have their own web page, publish pictures, add own picture to the profile?

3. More open to things they are familiar with?

4. Interest for downloading/saving things from internet (e.g. music, pictures, text)?

5. After learning something they get motivated to try at home?

6. Are they interested in learning to download pictures from camera and this kind of things? Do they know how to use the camera? Do they also make videos or just pictures?

7. Is there any problem in the environment that difficult the classes? Ex.: license to programs, Internet connection, air conditioner.

8. Are they interested in doing and sharing PowerPoint presentations by e-mail? (Personal, their photos or general sunset).

9. Taking notes?

10. Have you noticed any changes in the profile of the participants from when you started teaching from now? 